\title{
ESTERCO CAPRINO NA COMPOSIÇÃO DE SUBSTRATOS PARA FORMAÇÃO DE MUDAS DE MAMOEIRO
}

\section{Goat manure used in substrate composition for formation of papaya seedlings}

\author{
Wildjaime Bergmam Medeiros de Araújo ${ }^{1}$, Renato Dantas Alencar², Vander Mendonça ${ }^{3}$, \\ Erika Valente de Medeiros ${ }^{2}$, Romeu de Carvalho Andrade ${ }^{2}$, Rychardson Rocha de Araújo ${ }^{1}$
}

\begin{abstract}
RESUMO
Conduziu-se este trabalho, com o objetivo de avaliar a utilização de esterco caprino na composição de substratos para a formação de mudas de mamoeiro. $O$ delineamento experimental adotado foi o de blocos casualizados com cinco tratamentos e quatro repetições, sendo cada parcela constituída por oito plantas. Os tratamentos constaram de misturas composta por: $100 \%$ plantmax; $50 \%$ terra, $25 \%$ plantmax, $25 \%$ de esterco bovino; $50 \%$ terra, $25 \%$ plantmax, $25 \%$ esterco caprino; $30 \%$ terra, $35 \%$ plantmax, $35 \%$ esterco bovino; $30 \%$ terra, $35 \%$ plantmax, $35 \%$ esterco caprino. As variáveis analisadas foram: altura de planta; diâmetro do colo; número de folhas, comprimento de raiz; matéria seca da parte aérea e matéria seca da raiz. Os dados demonstram que a mistura mais eficiente para a formação de mudas de mamoeiro foi de $30 \%$ terra, 35\% Plantmax, $35 \%$ esterco caprino.
\end{abstract}

Termos para indexação: Carica papaya L., nutrição, qualidade de mudas.

\begin{abstract}
The objective of this work was to evaluate the utilization of goat manure in the substrate composition of papaya seedling formation. The experimental design used was of complete randomized blocks, with five treatments and four replications, and having eight plants per plot. The treatments consisted of substrate mixtures composed of: 100\% Plantmax; 50\% soil, 25\% Plantmax, and 25\% cattle manure; $50 \%$ soil, 25\% Plantmax, and 25\% goat manure; 30\% soil, 35\% Plantmax, and 35\% cattle manure; $30 \%$ soil, $35 \%$ Plantmax, and 35\% goat manure. Plant height and diameter, number of leaves per plant, root length, and shoot and root dry mass were evaluated. Substrate composed of 30\% soil, 35\% Plantmax, and 35\% goat manure was most efficient for promoting growth.
\end{abstract}

Index terms: Carica papaya L., nutrition, quality of seedling.

(Recebido em 4 de outubro de 2007 e aprovado em 18 de agosto de 2009)

\section{INTRODUÇÃO}

Atualmente, o Brasil é o maior produtor mundial de mamão, com uma produção anual de 1.650 .000 toneladas e produtividade de 45,20 ton/ha, em uma área total de 36.500 ha, o que representa $31,57 \%$ da área plantada mundial (FAO, 2006), seguido do México (955.694 ton) e Nigéria (755.000 ton) (FAO, 2005). Mesmo sendo o maior produtor mundial de mamão, o Brasil é o terceiro exportador mundial, depois do México e Malásia, exportando 35.930 toneladas (Rankbrasil, 2006).

Os Estados da Bahia e do Espírito Santo concentram mais de $70 \%$ da área cultivada e da produção do País. Outros Estados do Brasil, principalmente da região Nordeste, estão recebendo incentivo para a produção do mamão.

A produtividade e a qualidade dos frutos de mamoeiro dependem muito dos tratos culturais dispensados às plantas desde a obtenção de sementes até a formação de mudas. Dentre os fatores que podem afetar a produção de mudas de boa qualidade, estão: a qualidade da semente, do substrato e do adubo utilizado, pois estes contribuem para melhor desenvolvimento e sanidade da muda (Yamanishi, 2004).

No processo de produção de mudas, o estudo de um substrato adequado que forneça condições favoráveis ao desenvolvimento das plantas, é necessário, pois a qualidade da muda é fundamental na implantação de um pomar produtivo (Yamanishi 2004). O substrato deve apresentar condições adequadas à germinação e desenvolvimento do sistema radicular da mesma.

Segundo Negreiros et al. (2004), para a formação de mudas de mamoeiro vários misturas de substratos são sugeridas, como: solo e esterco de curral na proporção de 3:1 (Soares, 1998); solo, areia e esterco de curral curtido na proporção de $3: 1: 1$ ou ainda na proporção de $2: 1: 1$

\footnotetext{
1Universidade Federal Rural do Semi-Árido/UFERSA - Cx. P. 137 - 59.625-900 - Mossoró, RN - wildjaime@hotmail.com, rychardsonrocha@hotmail.com 2Universidade Federal Rural do Semi-Árido/UFERSA. - Mossoró, RN

3Universidade Federal Rural do Semi-Árido/UFERSA - Mossoró, RN
} 
(Trindade \& Oliveira, 1999), esterco de curral curtido, carvão vegetal, solo e areia na proporção de $2: 1: 1: 1 \mathrm{v} / \mathrm{v}$ (Mendonça et al., 2003)

Os melhores substratos devem apresentar, entre outras importantes características, fácil disponibilidade de aquisição e transporte, ausência de patógenos, riqueza em nutrientes essenciais, $\mathrm{pH}$ adequado, boa textura e estrutura (Silva et al., 2001).

A utilização de substratos orgânicos com características adequadas à espécie plantada possibilita redução do tempo de cultivo e do consumo de insumos, como fertilizantes químicos, defensivos e mão-de-obra (Fermino \& Kampf, 2003).

Severino et al. (2006), quantificou o teor de nutrientes de 11 materiais potencialmente utilizáveis para produção de mudas, na Região Nordeste e verificou que nenhum possuía composição química suficiente para ser utilizado como único componente, pois sempre há pelo menos um elemento em baixa concentração, de forma que os substratos devem, preferencialmente, ser formulados com misturas de materiais orgânicos que se complementem, tanto físico quanto quimicamente.

Objetivou-se, neste trabalho, avaliar o esterco caprino na composição de substratos para a formação de mudas de mamoeiro.

\section{MATERIAL E MÉTODOS}

O ensaio foi conduzido no viveiro de produção de mudas, coberto com tela que permite $50 \%$ de entrada de luz, da Universidade Federal Rural do Semiárido (UFERSA), no período de abril a maio de 2007.

O delineamento experimental adotado foi o de blocos casualizados com cinco tratamentos e quatro repetições, sendo cada parcela formada por oito plantas úteis. Os tratamentos constaram de misturas de substratos contendo: $\mathrm{T}_{1}=100 \%$ plantmax; $\mathrm{T}_{2}=50 \%$ terra, $25 \%$ plantmax, $25 \%$ de esterco bovino; $\mathrm{T}_{3}=50 \%$ terra, $25 \%$ plantmax, $25 \%$ esterco caprino; $\mathrm{T}_{4}=30 \%$ terra, $35 \%$ plantmax,
$35 \%$ esterco bovino; $\mathrm{T}_{5}=30 \%$ terra, $35 \%$ plantmax, $35 \%$ esterco caprino.

Utilizaram-se sementes de mamoeiro da cultivar Sunrise Solo. A semeadura foi realizada em recipientes com capacidade de $180 \mathrm{~mL}$ da mistura do substrato, com profundidade de $1,5 \mathrm{~cm}$, sendo colocadas três sementes por recipiente. $\mathrm{O}$ desbaste das mudas foi feito quando as mesmas apresentavam cerca de $5 \mathrm{~cm}$ de altura, deixando-a mais vigorosa.

A irrigação foi feita manualmente com utilização de um regador, sendo as mudas irrigadas duas vezes ao dia. $\mathrm{O}$ controle fitossanitário foi realizado conforme recomendações, para a cultura, de maneira uniforme em todas as parcelas. A germinação iniciou aos 12 dias após a semeadura, e aos 35 dias foram feitas as avaliações de altura de planta, diâmetro do colo, numero de folhas comprimento de raiz, matéria secas da parte aérea é matéria seca da raiz e matéria seca total.

A determinação da altura da muda e comprimento da raiz foi realizada com uma régua graduada em milímetro. A altura foi obtida medindo-se a distância entre o colo e o ápice da muda, já a raiz foi obtida medindo-se a distância do colo até o ápice da raiz. Na determinação do diâmetro do colo foi utilizado um paquímetro digital com valores expresso em mm.

A matéria seca da raiz e da parte aérea foi obtida após secagem em estufa de circulação forçada de ar a 60 ${ }^{\circ} \mathrm{C}$, até atingirem peso constante, procedendo, em seguida, à pesagem em balança analítica.

Os resultados foram submetidos à análise de variância e as médias dos dados foram comparados pelo teste Tukey, ao nível de 5\% de probabilidade (Gomes, 2000). As análises foram realizadas pelo programa computacional Sistema para Análise de Variância - SISVAR (Ferreira, 2000).

\section{RESULTADOS E DISCUSSÃO}

O resultado da análise química dos substratos utilizados neste experimento encontra-se na Tabela 1.

Tabela 1 - Resultados da análise química dos substratos utilizados na produção de mudas de mamoeiro. UFERSA. Mossoró-RN, 2007.

\begin{tabular}{lccccc}
\hline & $\mathrm{T}^{*}$ & $\mathrm{~T} 2$ & $\mathrm{~T} 3$ & $\mathrm{~T} 4$ & $\mathrm{~T} 5$ \\
\hline $\mathrm{P}\left(\mathrm{mg} \mathrm{kg}^{-1}\right)^{* *}$ & 399,16 & 136,22 & 150,7 & 188,7 & 233,8 \\
$\mathrm{~K}+\left(\mathrm{cmol}_{\mathrm{c}} \mathrm{dm}^{-3}\right)$ & 1,09 & 3,06 & 7,24 & 4,92 & 11,39 \\
$\mathrm{Ca}^{2+}\left(\mathrm{cmol}_{\mathrm{c}} \mathrm{dm}^{-3}\right)$ & 14,7 & 5,7 & 5,7 & 6,20 & 8,7 \\
$\mathrm{Mg}^{2+}\left(\mathrm{cmol}_{\mathrm{c}} \mathrm{dm}^{-3}\right)$ & 4,4 & 2,9 & 3,9 & 4,2 & 4,1 \\
\hline
\end{tabular}

"( T1 $=100 \%$ plantmax; T2 $=50 \%$ terra, 25\% plantmax, 25\% de esterco bovino; T3 $=50 \%$ terra, $25 \%$ plantmax, $25 \%$ esterco caprino; $\mathrm{T} 4=30 \%$ terra, $35 \%$ plantmax, $35 \%$ esterco bovino; $\mathrm{T} 5=30 \%$ terra, $35 \%$ plantmax, $35 \%$ esterco caprino). ${ }^{* *}$ Extrator duplo ácido 
Pela análise de variância, observou-se que houve diferença significativa $(P<0,05)$ para os tratamentos utilizados nas variáveis altura das mudas, diâmetro do caule, número de folhas, matéria seca da parte aérea e matéria seca da raiz. Na Figura 1, observa-se que as mudas de mamoeiro apresentaram maior altura, no substrato que continha $30 \%$ terra, $35 \%$ plantmax, $35 \%$ esterco caprino, que foi superior aos demais tratamentos, apresentando uma altura média de $9,40 \mathrm{~cm}$. Esta foi seguida pela média do substrato com $50 \%$ terra, $25 \%$ plantmax, $25 \%$ esterco caprino, que obteve $8,70 \mathrm{~cm}$ que difere estatisticamente das demais. A diferença média entre o melhor tratamento e o pior tratamento foi de quase $50 \%$ e a única diferença existente entre eles é o tipo de esterco que é mostrado na qual observa-se Tabela 1, possuindo maior concentração dos elementos fósforo, potássio e cálcio. Mendonça et al. (2003) utilizando diferentes substratos e recipientes na produção de mudas de mamoeiro 'Surinse solo', obtiveram mudas mais altas em substrato que continha esterco de curral, inclusive encontrando maior eficiência que o substrato comercial, quando utilizou saco para a produção das mudas.

O diâmetro das mudas (Figura 2), obteve resultados semelhantes ao observado para a altura das mudas, apresentando uma diferença média de cerca de $41 \%$ entre os substratos: $30 \%$ terra, $35 \%$ plantmax, $35 \%$ esterco caprino e o $30 \%$ terra, $35 \%$ plantmax, $35 \%$ esterco bovino. Vale ressaltar que ambos possuem $35 \%$ do substrato comercial plantmax, porém, quando este é utilizado isoladamente, possui uma eficiência estatisticamente inferior ao substrato $30 \%$ terra, $35 \%$ plantmax, $35 \%$ esterco caprino, e estatisticamente, igual ao com $30 \%$ terra, $35 \%$ plantmax, $35 \%$ esterco bovino.

$\mathrm{O}$ número de folhas respondeu melhor aos tratamentos que continham esterco caprino que diferiram estatisticamente dos demais, inclusive quando utilizado apenas o substrato comercial, mostrando que o componente da mistura que mais se destaca é o esterco caprino (Figura 3).

Negreiros et al. (2005), estudando diferentes substratos na formação de mudas de mamoeiro do grupo solo obteve maior número de folhas por planta no substrato composto por esterco de curral, solo, areia e vermiculita na proporção de 2:1:1:1 v/v, em relação ao substrato ao que continha plantmax, esterco de curral, solo e areia nas proporções 1:1:1:1 v/v.

Comportamento semelhante foi visto nas variáveis matéria seca da parte aérea (Figura 4) e matéria seca da raiz (Figura 5) cujos tratamentos mais eficientes foram os que continham esterco caprino.

A utilização de esterco bovino para a produção de mudas de mamoeiro é bastante utilizada e recomendada por Lima (1996). Pontes (1991) ao estudar substratos para a formação de mudas de mamoeiro na Amazônia ocidental, também recomenda a utilização de esterco bovino na composição do substrato, mesmo na ausência de adubação química. Isso é explicado pelo benefício que a matéria orgânica adicionada ao substrato traz pela melhoria no que

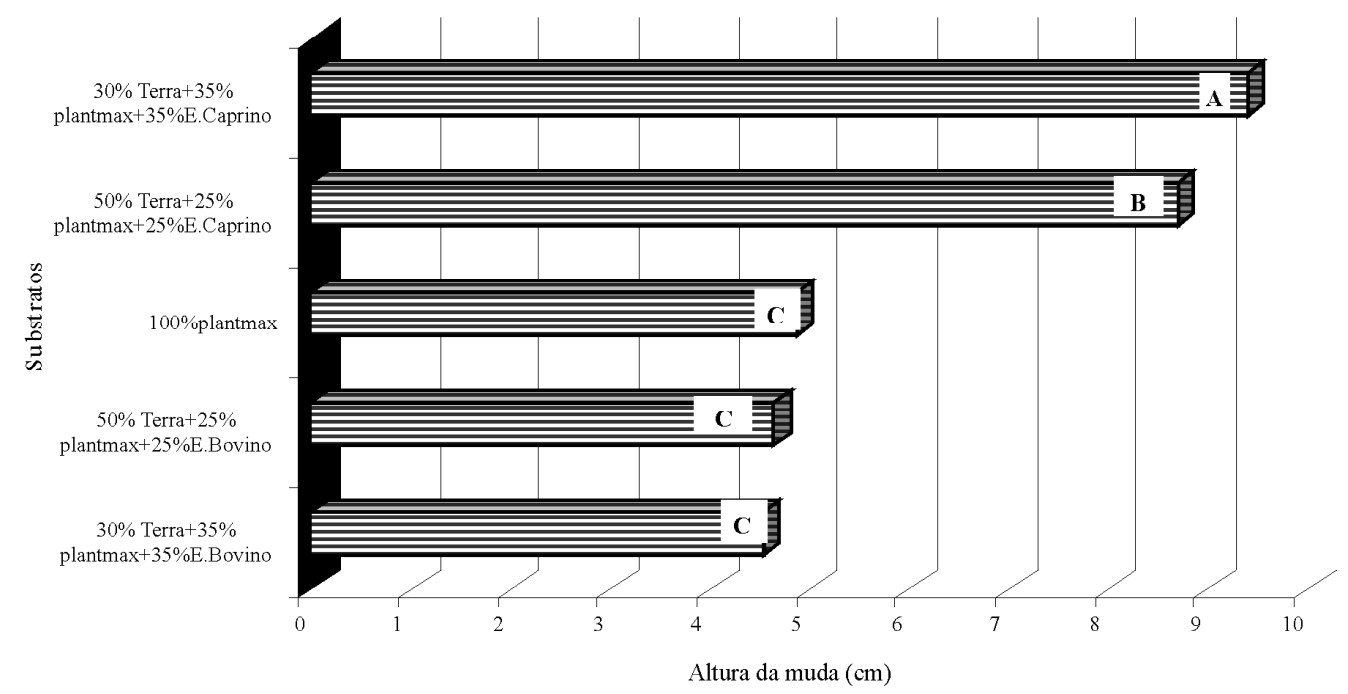

Figura 1 - Altura de mudas de mamoeiro cultivadas em substratos contendo proporções de esterco caprino e bovino. Mossoró-RN, 2007. 


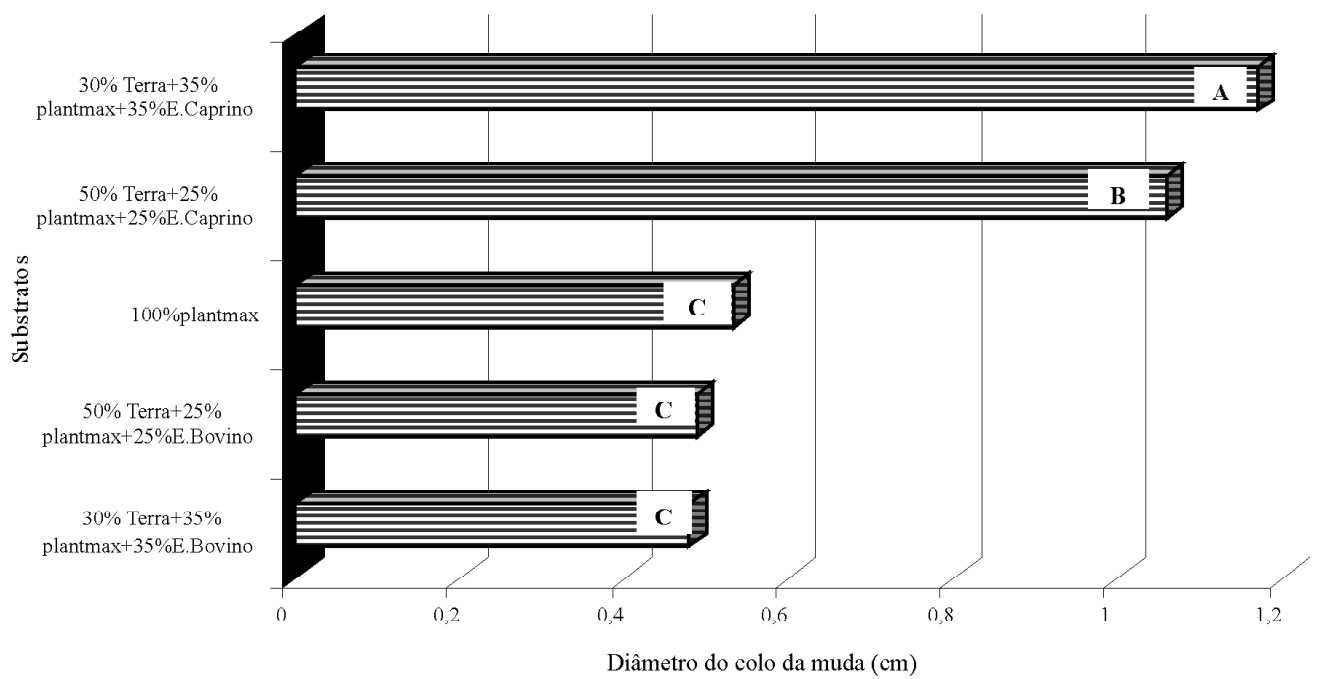

Figura 2 - Diâmetro do colo de mudas de mamoeiro cultivadas em substratos contendo proporções de esterco caprino e bovino. Mossoró-RN, 2007.

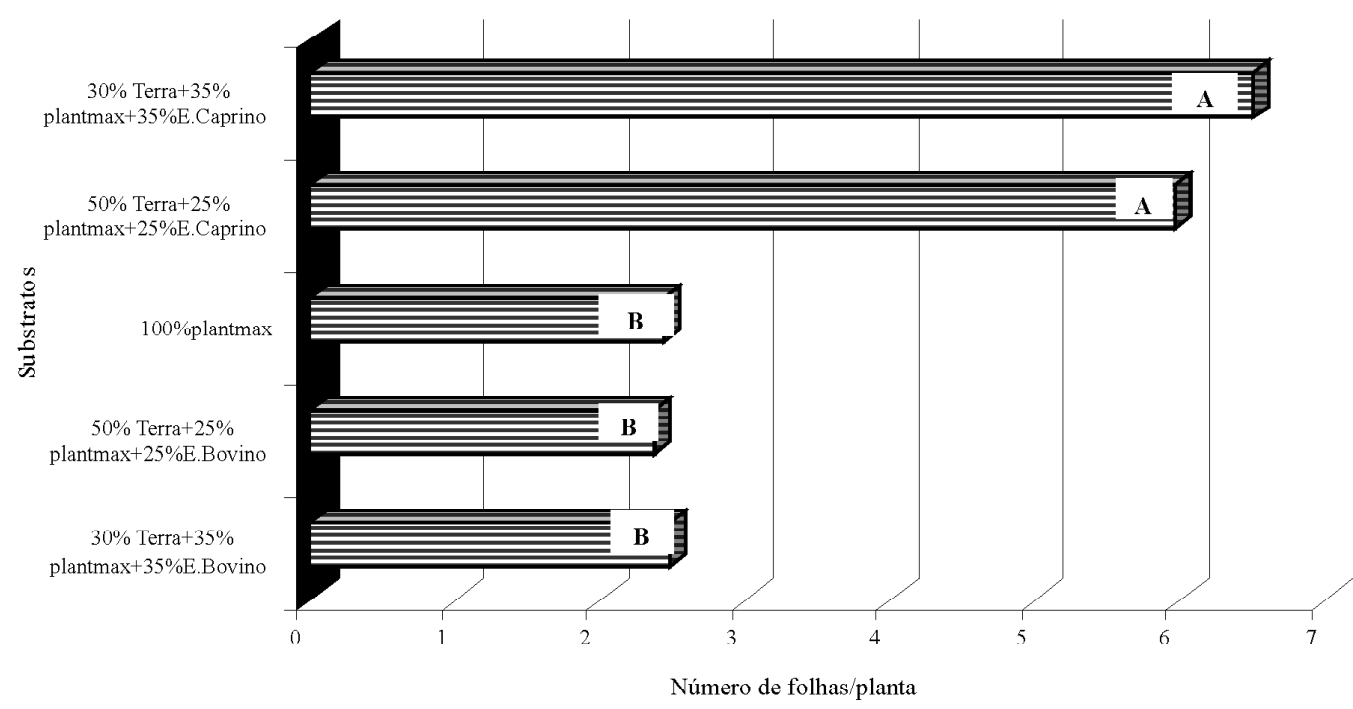

Figura 3 - Número de folhas de planta de mamoeiro cultivados em substratos contendo proporções de esterco caprino e bovino. Mossoró-RN, 2007.

diz respeito às características químicas, físicas e microbiológicas do solo, o que acarreta em um benefício ao crescimento e desenvolvimento das plantas (Bento, 1997).

Mendonça et al. (2007), ao estudarem o comportamento de mudas de mamoeiro submetidas a diferentes proporções de composto orgânico que continha esterco, observaram equações lineares crescentes, sendo a melhor dose a maior dose testada, isto é, $40 \%$ para as variáveis altura de mudas, comprimento da raiz, número de folhas por planta, matéria seca da parte aérea, raiz e total. Esses dados corroboram com este trabalho e comprovam a importância do esterco na produção de mudas de mamoeiro.

O esterco caprino e ovino é um produto valioso e a sua utilização prevê tanto a possibilidade de recuperação de terrenos degradadosmportante alternativa de fonte de renda dos produtores. Alguns estudos examinaram o potencial de utilização do esterco de caprinos e ovinos e todos ressaltam o seu valor, tendo em vista as comparações 


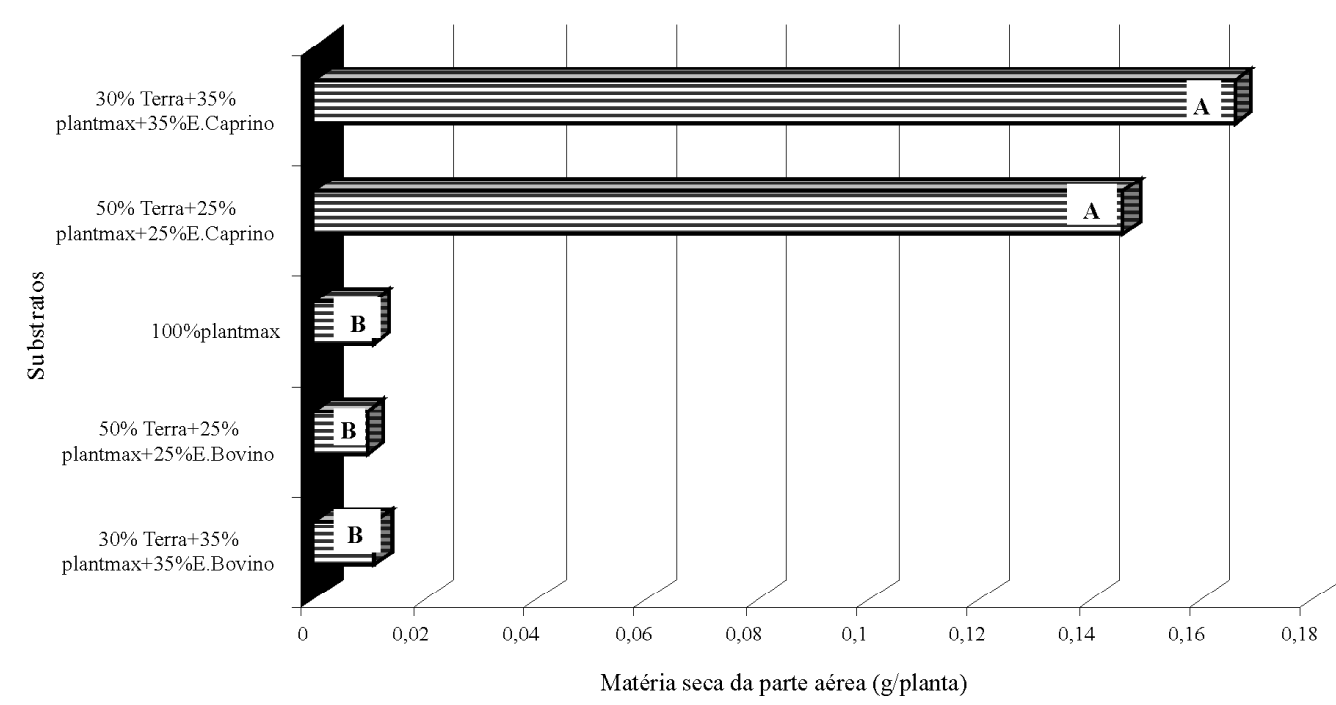

Figura 4 - Matéria seca da parte aérea de mudas de mamoeiro cultivadas em composições de substratos contendo proporções de esterco caprino e bovino. Mossoró-RN, 2007.

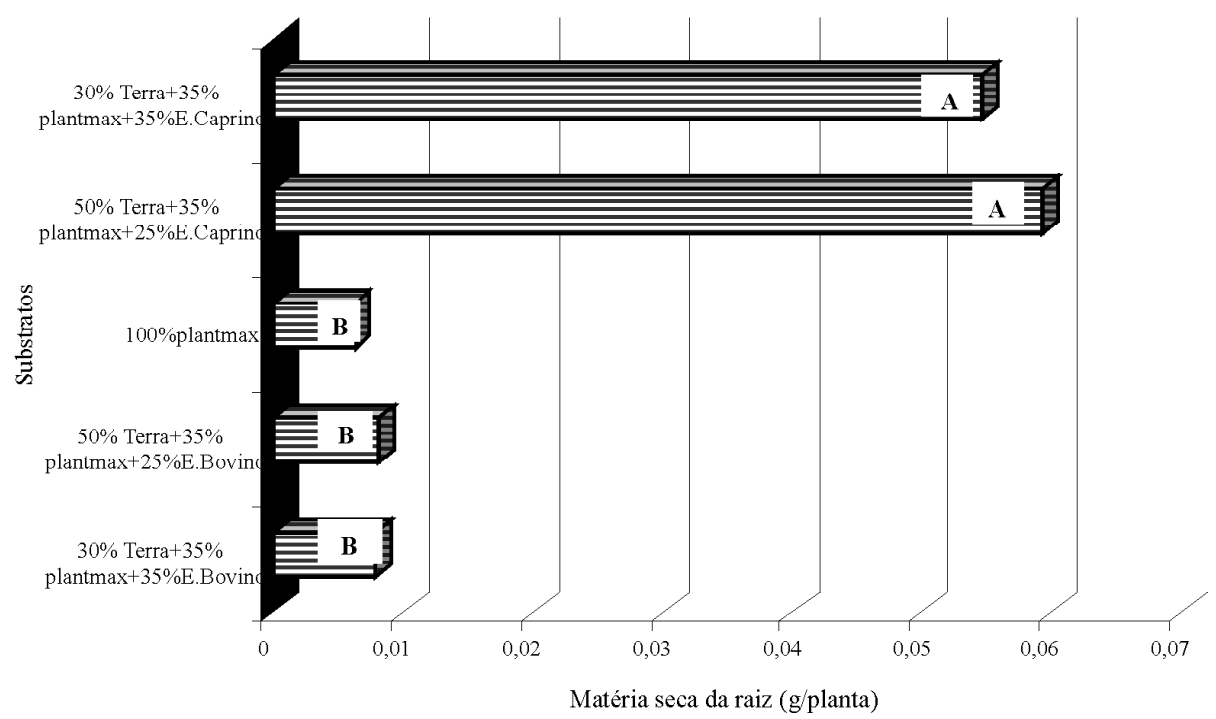

Figura 5 - Matéria seca da raiz de mudas de mamoeiro cultivadas em substratos contendo proporções de esterco caprino e bovino. Mossoró-RN, 2007.

feitas com o esterco de bovinos, entretanto, poucos dados existem na literatura quanto ao seu uso (Alves \& Pinheiro, 2008). O esterco de caprino é mais sólido e muito menos aquoso que o dos bovinos e suínos, tem a estrutura mais fofa, permitindo a aeração e por essa razão fermentam rapidamente, podendo ser aproveitados na agricultura, após um menor período de "curtição" que os demais (Henriques, 1997).

\section{CONCLUSÕES}

O esterco caprino influenciou positivamente no crescimento das mudas de mamoeiro, sendo observado que a mistura $30 \%$ terra, $35 \%$ plantmax e $35 \%$ esterco caprino constitui-se em um substrato adequado. Assim, a adição de esterco caprino na formulação de substratos é mais uma alternativa para a produção de mudas de mamoeiro. 


\section{REFERÊNCIAS BIBLIOGRÁFICAS}

ALVES, F.S.F.; PINHEIRO, R.R. O esterco cabrino e ovino como fonte de renda. Brasília: Embrapa, 2008. Disponível em: $<$ hnttp://Www.agricultura.gov.br/>. Acesso em: 6 mar. 2008.

BENTO, M.M. Fontes de matéria orgânica na composição de substratos para a produção de mudas micorrizadas de maracujazeiro. 1997. 59f. Dissertação (Mestrado em Fitotecnia)-Escola Superior de Agricultura Luis de Queiroz, Piracicaba, 1997.

FERMINO, M.H.; KAMPF, A.N. Uso do solo bom Jesus com condicionadores orgânicos como alternativa de substrato para plantas. Pesquisa Agropecuária Gaúcha, Porto Alegre, v.9, n.1/2, p.33-41, 2003.

FERREIRA, D.F. Análise estatística por meio do SISVAR Sistema para Análise de Variância - para Windows versão 4.0. In: REUNIÃO ANUAL DA REGIÃO BRASILEIRA DA SOCIEDADE INTERNACIONAL DE BIOMETRIA, 45., 2000, São Carlos. Anais... São Carlos: UFSCar, 2000. p.255-258.

FOOD AGRICULTURAL ORGANIZATION.Dados agrícolas sobre a cultura do mamão. Rome, 2005. Disponível em: 〈http://apps. fao.org $\rangle$. Acesso em: 8 jul. 2006.

\section{FOOD AGRICULTURAL ORGANIZATION.Dados} agrícolas sobre a cultura do mamão. Rome, 2006. Disponível em: 〈http://apps. faotorg $>$ Acesso em: 8 jul. 2006.

GOMES, F.P. Curso de estatística experimental. 14.ed. Piracicaba: USP, 2000. 477p.

HENRIQUES, R.C. Análise da fixação de nitrogênio por bactérias do gênero Rhizobium em diferentes concentrações de fósforo e matéria orgânica na cultura do feijão (Phaseolus vulgaris) em Rego Pólo. 1997. 29f. Monografia (Graduação em Agronomia)- Universidade Federal da Paraíba, Areia, 1997.

LIMA, M.L. de F.N. Efeito da composição do substrato na formação de mudas de mamoeiro cv. Sunrise Solo. In: CONGRESSO BRASILEIRO DE FRUTICULTURA, 14., 1996, Curitiba. Anais... Curitiba: IAPAR, 1996. p.295.

MENDONÇA, V.; ABREU, N.A.A.; SOUZA, H.A.; FERREIRA, E.A.; RAMOS, J.D. Diferentes níveis de composto orgânico na formulação de substrato para a produção de mudas de mamoeiro 'formosa'. Caatinga, v.20, n.1, p.49-53, jan./mar. 2007.
MENDONÇA, V.; ARAÚJO NETO, S.E. de; RAMOS, J.D.; PIO, R.; GONTIJO, T.C.A. Diferentes substratos e recipientes na formação de mudas de mamoeiro 'Sunrise Solo'. Revista Brasileira de Fruticultura, Jaboticabal, v.25, n.1, p.127-230, abr. 2003.

NEGREIROS, J.R.S.; ÁLVARES, V.S.; BRAGA, L.R.; BRUCKNER, C.H. Diferentes substratos na formação de mudas de maracujazeiro-amarelo. Revista Ceres, Viçosa, MG, v.51, n.294, p.243-345, 2004.

NEGREIROS, J.R.S.; BRAGA, L.R.; ÁLVARES, V. de S.; BRUCKNER, C.H. Diferentes substratos na formação de mudas de mamoeiro do grupo solo. Revista Brasileira de Agrociência, Pelotas, v.11, n.1, p.101-103, jan./mar. 2005.

PONTES, H.M. Substratos para a produção de mudas de mamoeiro (Carica papaya L.) na Amazônia Ocidental.

Revista da Universidade do Amazonas, Série Ciências Agrárias, Manaus, v.1, n.1, p.57-64, 1991.

RANKBRASIL. Disponível em: <http:// www.rankbrasil.com.bi $>$. Acesso em: 9 jul. 2006.

SEVERINO, L.S.; LIMA, R.L.; BELTRÃO, N.E.M. Composição química de onze materiais orgânicos utilizados em substratos para produção de mudas. Campina Grande: Embrapa, 2006. (Comunicado técnico, 27).

SILVA, R.P. da; PEIXOTO, J.R.; JUNQUEIRA, N.T.V. Influência de diversos substratos no desenvolvimento de mudas de maracujazeiro-azedo (Passiflora edulis Sims f. flavicarpa DEG). Revista Brasileira de Fruticultura, Jaboticabal, v.23, n.2, p.377-381, ago. 2001.

SOARES, N.B. Mamão Carica papaya L. In: FAHL, J.I.; CAMARGO, M.B.P.; PIZZINATTO, M.A.; BETTI, J.A.; MELO, A.M.T. de; MARIA, I.C. de; FURLANI, A.M.C. (Eds.). Instruções agrícolas para as principais culturas econômicas. Campinas: IAC, 1998. p.137-138. (Boletim, 200).

TRINDADE, A.V.; OLIVEIRA, J.R.P. Propagação e plantio. In: SANCHES, N.F.; DANTAS, J.L.L. O cultivo do mamão. Cruz das Almas: Embrapa Mandioca e Fruticultura, 1999. p.17-76. (Circular Técnica, 34).

YAMANISHI, O.K. et al. Different growth medium and fertilizer effects on papaya seedlings growth. Revista Brasileira Fruticultura, Jaboticabal, v.26, n.2, 2004. Disponível em: <http://, iwww.scielo.br/scielo.php?script=sci=arttext\&pid=S0100-1

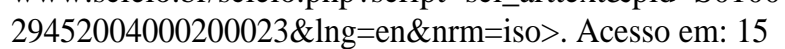
jun. 2007. 